Supporting Information

\title{
PEGylated quasi-ionic liquid electrolytes: fundamental physiochemical properties and electrodeposition of aluminium
}

Jingyun Jiang, ${ }^{[a]}$ Wancheng Zhao, ${ }^{[a]}$ Zhimin Xue ${ }^{[b]}$ Qingbo Li, ${ }^{[a]}$ Chuanyu Yan, ${ }^{[a]}$ and Tiancheng Mu${ }^{\star[a]}$

${ }^{a}$ Department of Chemistry, Renmin University of China, Beijing 100872, China.

${ }^{\mathrm{b}}$ Beijing Key Laboratory of Lignocellulosic Chemistry, College of Materials Science and Technology, Beijing Forestry University, Beijing 100083, China.

*Corresponding author. Tel: 86-10-62514925, Email: tcmu@ruc.edu.cn;

tcmu@chem.ruc.edu.cn 


\section{Content}

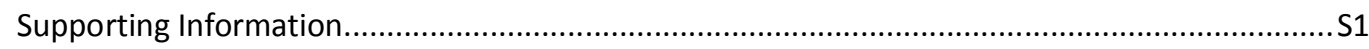

Table S1 The solubilities (g per $100 \mathrm{~g}$ PEG) of different salt in PEGs and water at 298.15 K. .........S3



Fig. S2 Photographs of the new salt-in-PEG electrolytes (up) and six months later. After six months, there were no changes in all PEGylated quasi-ionic liquid electrolytes...........................S5

Fig. S3 The origin ${ }^{1} \mathrm{H}$ NMR data of PEG 200 with or without salt................................................S6

Fig. S4 The IR spectra of PEGylated quasi-ionic liquid electrolyte. ............................................S7

Fig. S5 TGA results $\left(5 \mathrm{~K} \cdot \mathrm{min}^{-1}\right)$ for different salts, PEG, and PEGylated quasi-ionic liquid

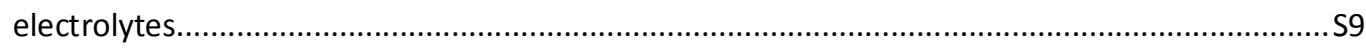

Fig. S6 Cross-section SEM images of Al deposition on the copper substrate. Electrodeposition was performed by the potentiostatic method $\left(-0.2 \vee v s \quad \mathrm{Al}^{3+} / \mathrm{Al}\right.$, (a); $-0.5 \vee v s \mathrm{Al}^{3+} / \mathrm{Al}$, (b)) in aluminum(III) chloride : $\mathrm{KCl}$ in PEG electrolyte at the molar ratio of $1: 3$ at $298.15 \mathrm{~K}$.

Fig. S7 Energy dispersive X-ray spectroscopy (EDX) analysis of aluminum deposition on copper substrate. The electrolyte was aluminium(III) chloride/1-ethyl-3-methylimidazolium ILs. And the electrodeposited condition was the same as the electrodeposition of aluminum in PEGylated quasi-ionic liquid electrolytes ILs. S12 
Table S1 The solubilities (g per $100 \mathrm{~g} \mathrm{PEG)} \mathrm{of} \mathrm{different} \mathrm{salt} \mathrm{in} \mathrm{PEGs} \mathrm{and} \mathrm{water} \mathrm{at} 298.15 \mathrm{~K}$.

\begin{tabular}{|c|c|c|c|}
\hline \multirow{2}{*}{ Salts } & \multicolumn{3}{|c|}{ Solubility (g per $100 \mathrm{~g}$ ) } \\
\hline & PEG 300 & PEG 400 & Water \\
\hline $\mathrm{NaBr}$ & 1.11 & 0.94 & $94.6^{\mathrm{a}}$ \\
\hline $\mathrm{NaCl}$ & 0.25 & 0.09 & $36^{a}$ \\
\hline $\mathrm{KBr}$ & 2.41 & 0.35 & $40.713^{b}$ \\
\hline $\mathrm{KCl}$ & 0.97 & 0.22 & $34^{\mathrm{a}}$ \\
\hline HCOONa & 0.25 & 0.19 & $94.9^{c}$ \\
\hline $\mathrm{CH}_{3} \mathrm{COONa}$ & 4.89 & 1.11 & $50.4^{c}$ \\
\hline $\mathrm{CH}_{3} \mathrm{COONH}_{4}$ & 6.96 & 0.89 & $148^{\mathrm{C}}$ \\
\hline $\mathrm{HCOONH}_{4}$ & 1.52 & 1.01 & $142.7^{\mathrm{c}}$ \\
\hline $\mathrm{NaNO}_{2}$ & 1.83 & 0.97 & $84.8^{c}$ \\
\hline $\mathrm{NaClO}_{3}$ & 0.94 & 0.41 & $100^{c}$ \\
\hline $\mathrm{NaSCN}$ & 3.97 & 2.15 & $151^{\mathrm{C}}$ \\
\hline $\mathrm{NH}_{4} \mathrm{Cl}$ & 2.17 & 2.04 & $39.5^{\mathrm{c}}$ \\
\hline $\mathrm{NaNO}_{3}$ & 2.12 & 1.28 & $91.2^{c}$ \\
\hline $\mathrm{NaClO}_{4}$ & 7.39 & 1.30 & $205^{c}$ \\
\hline
\end{tabular}

${ }^{a}$ Data taken from reference (1). ${ }^{b}$ Data taken from reference (2). ${ }^{c}$ Data taken from reference (3). 


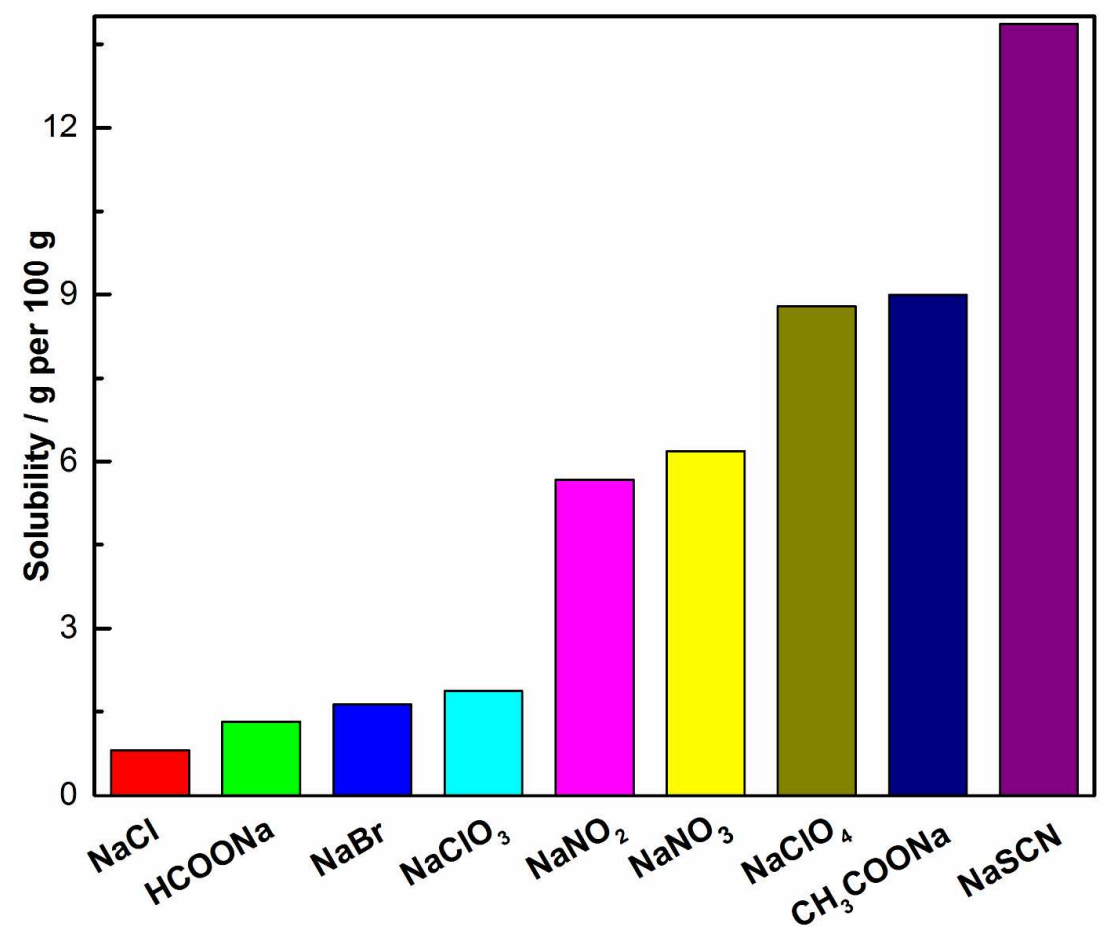

Fig. S1 The solubilities of sodium salts in PEG 200 at $298.15 \mathrm{~K}$. 


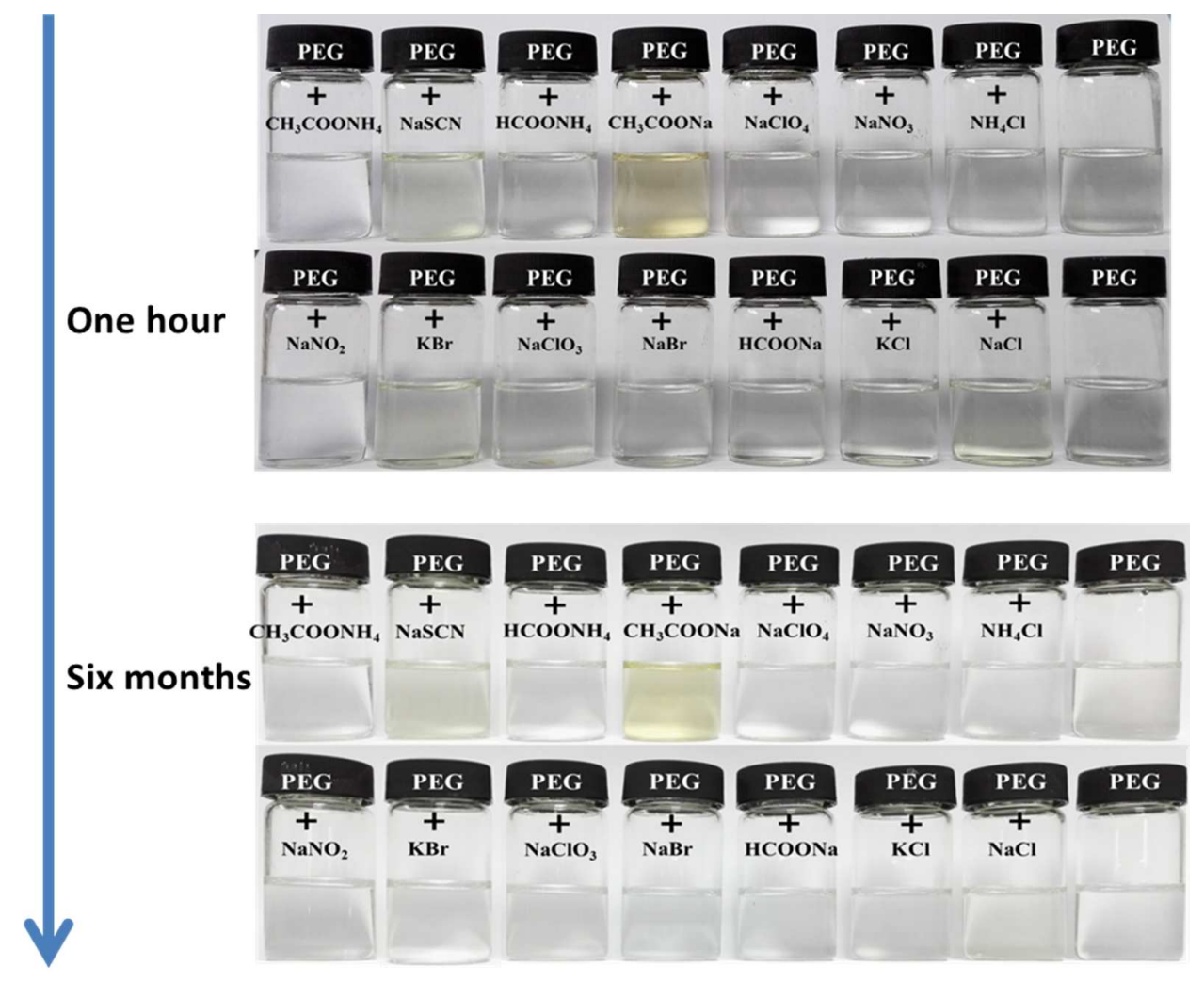

Fig. S2 Photographs of the new salt-in-PEG electrolytes (up) and six months later. After six months, there were no changes in all PEGylated quasi-ionic liquid electrolytes. 


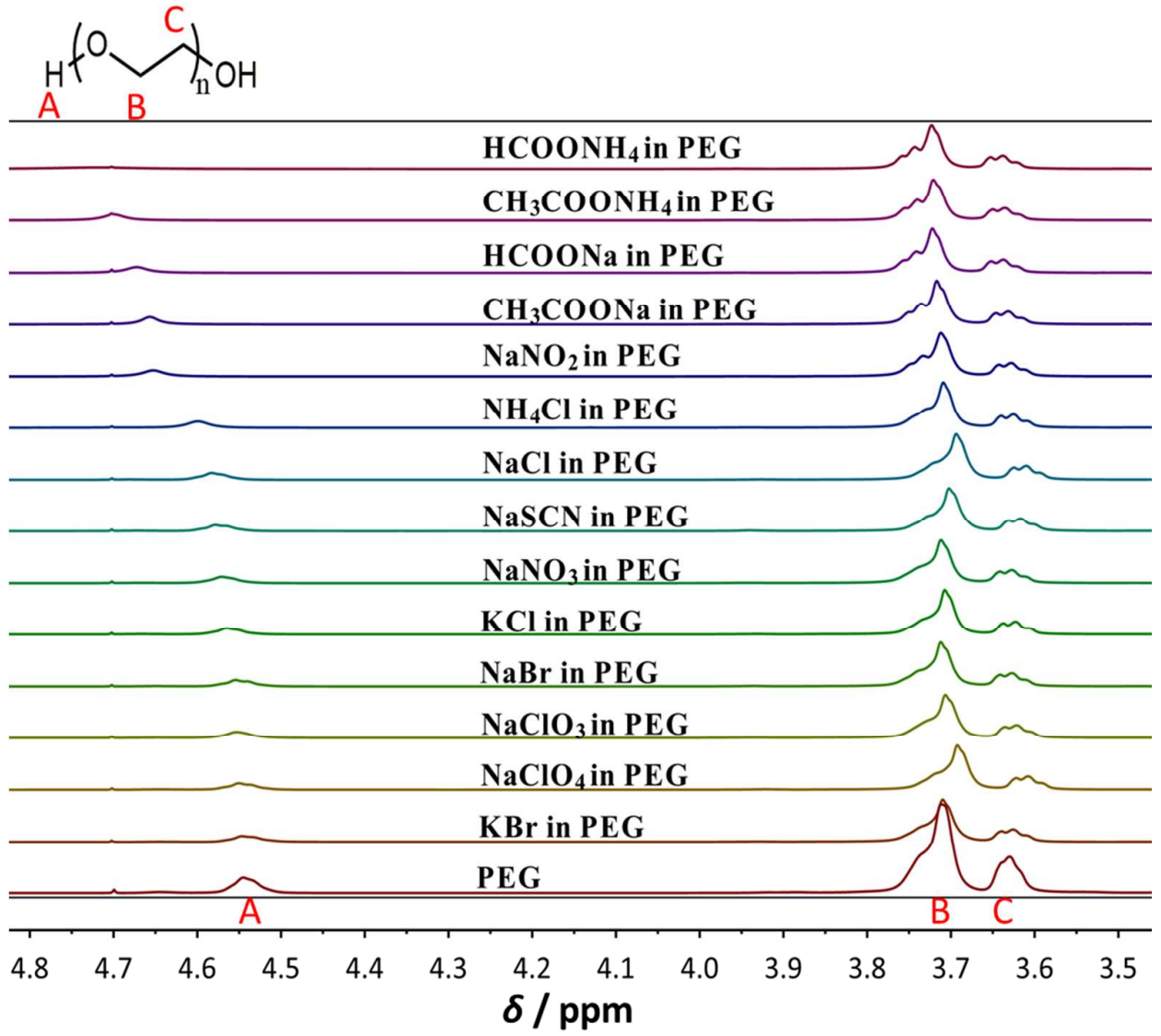

Fig. S3 The origin ${ }^{1} \mathrm{H}$ NMR data of PEG 200 with or without salt. 


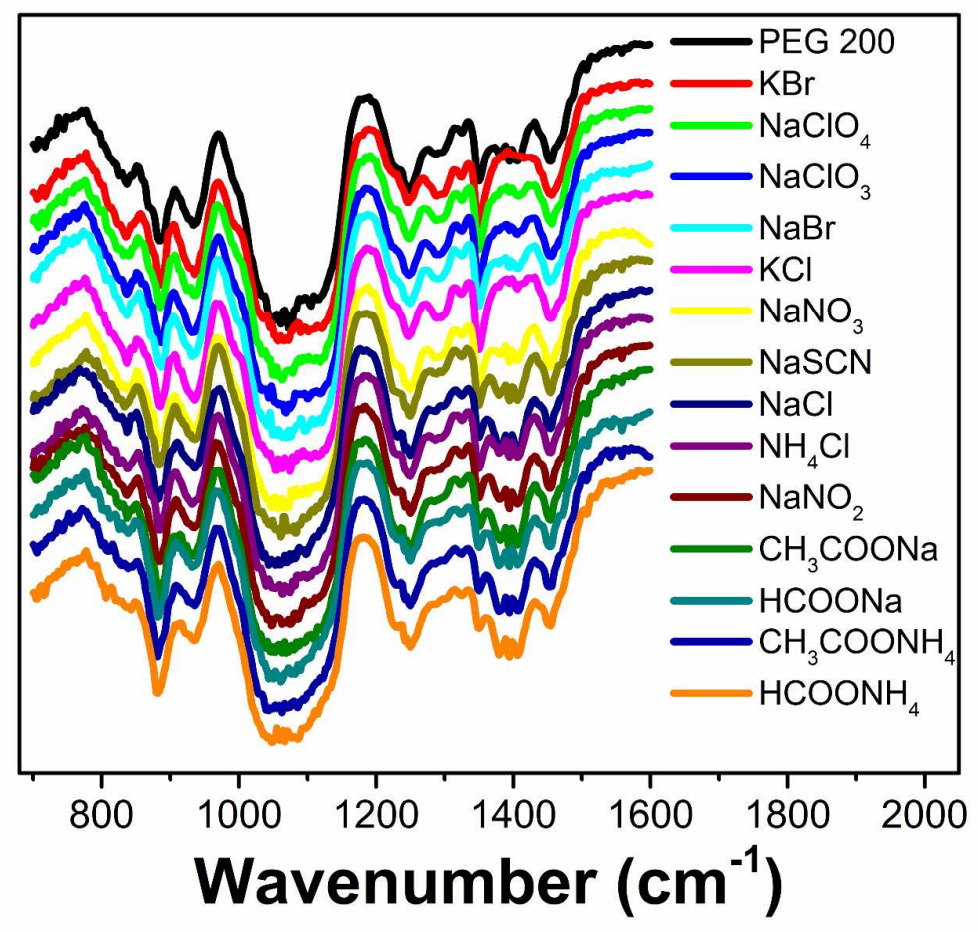

Fig. S4 The IR spectra of PEGylated quasi-ionic liquid electrolyte. 



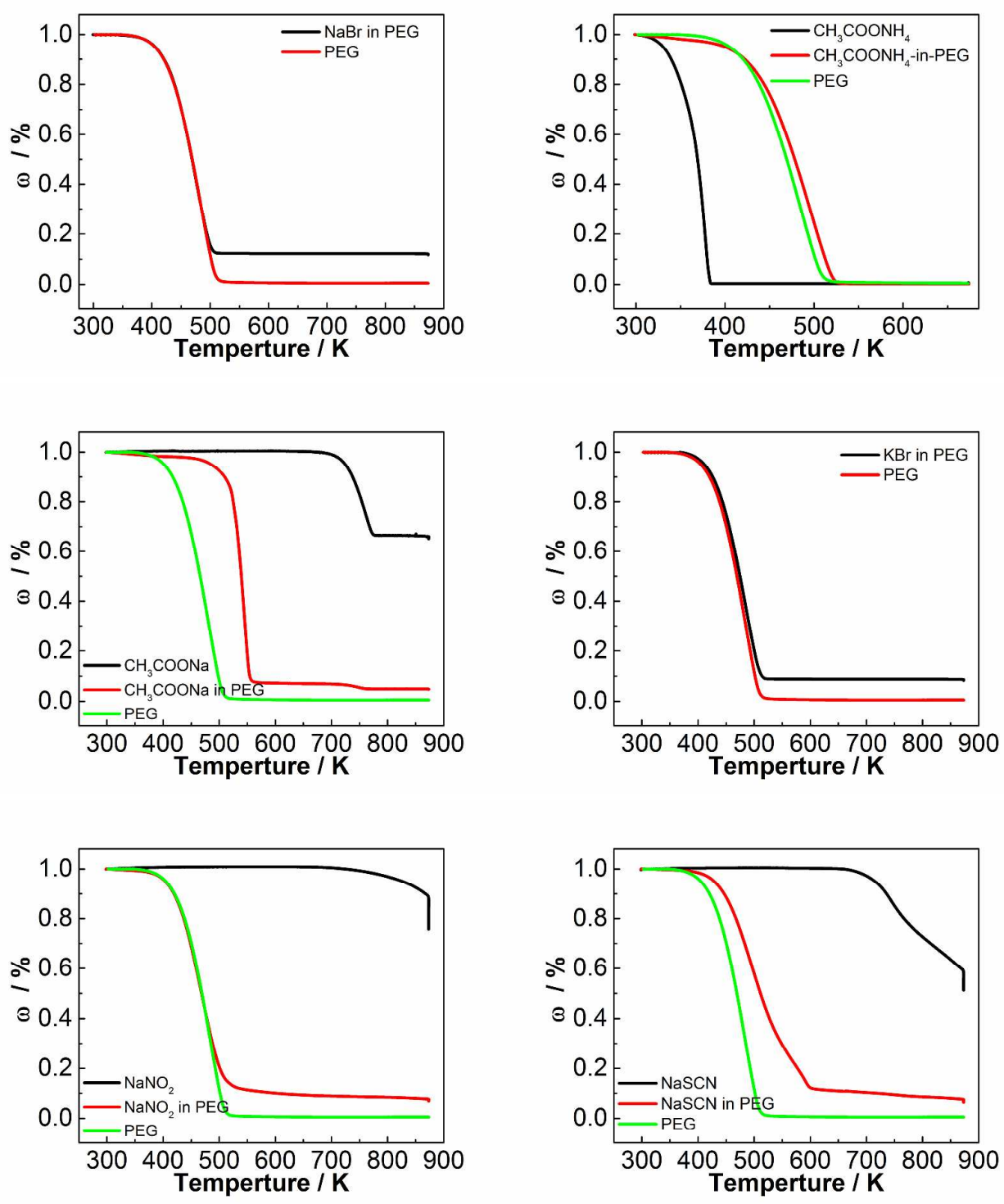

Fig. S5 TGA results $\left(5 \mathrm{~K} \cdot \mathrm{min}^{-1}\right)$ for different salts, PEG, and PEGylated quasi-ionic liquid electrolytes.

The decomposed temperature of $\mathrm{CH}_{3} \mathrm{COONH}_{4}$ is lower than PEG 200. For $\mathrm{CH}_{3} \mathrm{COONH}_{4}$-in-PEG system, $\mathrm{CH}_{3} \mathrm{COONH}_{4}$ decomposes firstly and following the decomposition of PEG. Both $\mathrm{CH}_{3} \mathrm{COONH}_{4}$ and PEG are burn out.

$\mathrm{HCOONH}_{4}$ has two decompose temperature: one is lower than PEG and the other is higher than PEG. For $\mathrm{HCOONH}_{4}$-in-PEG system, both of them decompose sufficiently. 
The decomposed temperature of $\mathrm{NaNO}_{3}$ is similar with PEG 200. For $\mathrm{NH} 4 \mathrm{Cl}$-in-PEG system, both PEG and $\mathrm{NH}_{4} \mathrm{Cl}$ burn out fully.

The decomposed temperature of $\mathrm{NaSCN}, \mathrm{HCOONa}, \mathrm{CH}_{3} \mathrm{COONa}, \mathrm{NaClO}_{4}, \mathrm{NaNO}_{3}$, and $\mathrm{NaNO}_{2}$ are higher than PEG 200, and there still exists something even the temperature up to $873.15 \mathrm{~K}$ during the TGA. For those PEGylated quasi-ionic liquid electrolytes, PEG burns out fully at first, while salts do not decomposed sufficiently.

The decomposed temperature of $\mathrm{NaClO}_{3}$ is higher than PEG 200, and there still exists something even the temperature up to $873.15 \mathrm{~K}$ during the TGA. For $\mathrm{NaClO}_{3}$-in-PEG system, PEG burns out fully at first, while $\mathrm{NaClO}_{3}$ does not decomposed sufficiently. During the TGA, there is a small parcel at 523.15 K, which may contribute to the metallic oxide of $\mathrm{Na}$.

The decomposed temperature of $\mathrm{KBr}, \mathrm{NaBr}$, and $\mathrm{KCl}$ are higher than $873.15 \mathrm{~K}$. For those PEGylated quasi-ionic liquid electrolytes, PEG burns out fully at first, while salts do not decomposed actually. 

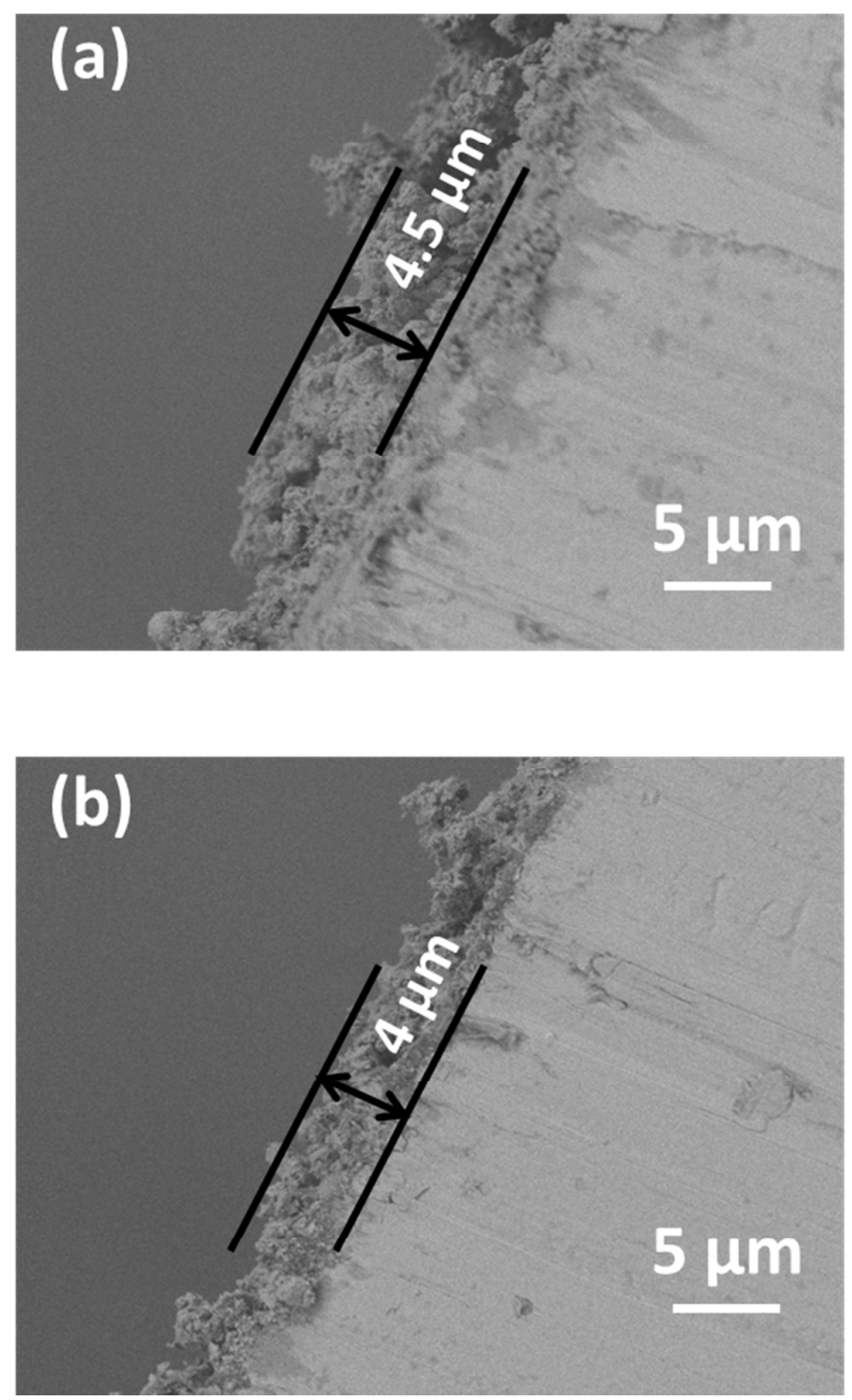

Fig. S6 Cross-section SEM images of Al deposition on the copper substrate. Electrodeposition was performed by the potentiostatic method $\left(-0.2 \mathrm{~V} v s \mathrm{Al}^{3+} / \mathrm{Al}\right.$, (a); $-0.5 \mathrm{~V} v s \mathrm{Al}^{3+} / \mathrm{Al}$, (b)) in aluminum(III) chloride : $\mathrm{KCl}$ in PEG electrolyte at the molar ratio of $1: 3$ at $298.15 \mathrm{~K}$. 


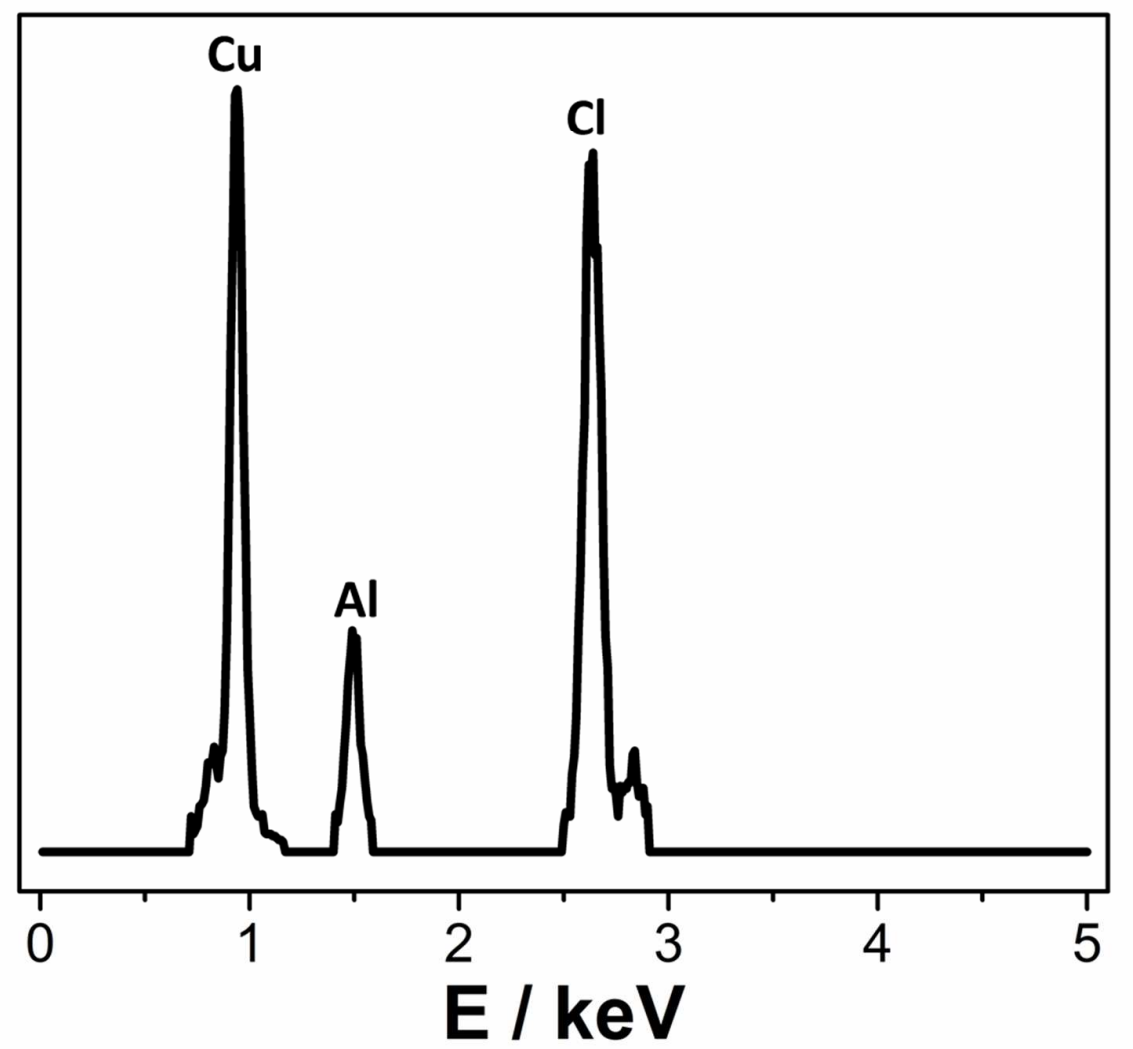

Fig. S7 Energy dispersive X-ray spectroscopy (EDX) analysis of aluminum deposition on copper substrate. The electrolyte was aluminium(III) chloride/1-ethyl-3-methylimidazolium ILs. And the electrodeposited condition was the same as the electrodeposition of aluminum in PEGylated quasi-ionic liquid electrolytes ILs. 


\section{Reference}

(1) S. P. Pinho and E. A. Macedo, Solubility of $\mathrm{NaCl}, \mathrm{NaBr}$, and $\mathrm{KCl}$ in Water, Methanol, Ethanol, and Their Mixed Solvents. J. Chem. Eng. Data 2005, 50, 29-32.

(2) S. P. Pinho and E. A. Macedo, Experimental measurement and modelling of $\mathrm{KBr}$ solubility in water, methanol, ethanol, and its binary mixed solvents at different temperatures. J. Chem. Thermodyn. 2002, 34, 337-360.

(3) D. R. Lide, CRC Handbook of Physics and Chemistry 2001. 